\title{
Image-Based Machine Learning Characterizes Root Nodule in Soybean Exposed to Silicon
}

\author{
Yong Suk Chung ${ }^{1+}$, Unseok $\mathrm{Lee}^{2 \dagger}$, Seong $\mathrm{HeO}^{3+}$, Renato Rodrigues Silva ${ }^{4}$, Chae-In $\mathrm{Na}^{5}$ \\ and Yoonha Kim ${ }^{6 *}$ \\ ${ }^{1}$ Department of Plant Resources and Environment, Jeju National University, Jeju-si, South Korea, ${ }^{2}$ Smart Farm Research \\ Center, Korea Institute of Science and Technology, Gangneung-si, South Korea, ${ }^{3}$ Department of Horticulture, Kongju \\ National University, Yesan, South Korea, ${ }^{4}$ Institute of Mathematics and Statistics, Federal University of Goiás, Goiânia, Brazil, \\ ${ }^{5}$ Department of Agronomy, Gyeongsang National University, Jinju-si, South Korea, ${ }^{6}$ School of Applied Life Science, \\ Kyungpook National University, Daegu, South Korea
}

OPEN ACCESS

Edited by:

Roger Deal,

Emory University, United States

Reviewed by:

Agnieszka Klimek-Kopyra, University of Agriculture in Krakow,

Poland

Marc Libault,

University of Nebraska-Lincoln,

United States

${ }^{*}$ Correspondence:

Yoonha Kim

kyh1229@knu.ac.kr;

kimyoonha7979@gmail.com

${ }^{t}$ These authors have contributed equally to this work

Specialty section:

This article was submitted to Technical Advances in Plant Science,

a section of the journal

Frontiers in Plant Science

Received: 14 December 2019

Accepted: 06 October 2020

Published: 28 October 2020

Citation:

Chung YS, Lee U, Heo S,

Silva RR and Na C-I and Kim Y (2020) Image-Based Machine Learning

Characterizes Root Nodule

in Soybean Exposed to Silicon.

Front. Plant Sci. 11:520161.

doi: 10.3389/fpls.2020.520161
Silicon promotes nodule formation in legume roots which is crucial for nitrogen fixation. However, it is very time-consuming and laborious to count the number of nodules and to measure nodule size manually, which led nodule characterization not to be study as much as other agronomical characters. Thus, the current study incorporated various techniques including machine learning to determine the number and size of root nodules and identify various root phenotypes from root images that may be associated with nodule formation with and without silicon treatment. Among those techniques, the machine learning for characterizing nodule is the first attempt, which enabled us to find high correlations among root phenotypes including root length, number of forks, and average link angles, and nodule characters such as number of nodules and nodule size with silicon treatments. The methods here could greatly accelerate further investigation such as delineating the optimal concentration of silicon for nodule formation.

Keywords: phenomics, root phenotype, nodule count, nodule size, legume, machine learning, image process, high-throughput phenotyping

\section{INTRODUCTION}

Soybean is regarded as one of the three major crops in the world because of its nutritional value (Bellaloui et al., 2013). For this reason, soybean is broadly cultivated not only for its use as an ingredient in foods, such as soy source, soybean paste, and tofu but also for livestock feed (He and Chen, 2013). Global soybean demands have grown steadily in recent years (Armah et al., 2011), fueling the application of chemical nutrients to increase grain yield. As a result, nitrogen $(\mathrm{N})$, potassium $(\mathrm{K})$, and phosphorus $(\mathrm{P})$ are widely used in crop cultivation (Bharati et al., 1986). Among these nutrients, $\mathrm{N}$ is the most essential for plant growth, so vast quantities of nitrogenous fertilizer are used to improve crop yields (Tegeder and Masclaux-Daubresse, 2018).

Most plants need to uptake $\mathrm{N}$ from the soil and water via plant roots as inorganic ions, ammonium $\left(\mathrm{NH}_{4}{ }^{+}\right)$, and nitrate $\left(\mathrm{NO}_{3}{ }^{-}\right)$to maintain growth and development such as leaf expansion, stem growth and production of amino acid (Masclaux-Daubresse et al., 2010; Bloom, 2015). However, legumes form symbioses with $\mathrm{N}_{2}$-fixing bacteria in the soil that biologically convert atmospheric $\mathrm{N}_{2}$ to $\mathrm{NH}_{3}$ for use in the plant. This symbiotic relationship generates root nodules on the host plant in which the rhizobia are found as $\mathrm{N}_{2}$-fixing 
bacteroids (Schultze and Kondorosi, 1998; Stougaard, 2000; Rentsch et al., 2007). Interestingly, such nodulation and $\mathrm{N}_{2}$ fixation depend on an adequate supply of both macroand micronutrients (Smith, 1982). In particular, among the micronutrients, iron $(\mathrm{Fe})$ plays an important role in nodule formation by affecting the activation of the legume host and rhizobia (Brear et al., 2013). Molybdenum (Mo) is known as an important micronutrient for biological $\mathrm{N}$-fixation in soil because Mo participates biochemical redox reaction when $\mathrm{N}$-fixing bacteria converts atmospheric $\mathrm{N}_{2}$ into ammonium- $\mathrm{N}$ and nitrate-N forms in nodules (Mendel and Hänsch, 2002; Alam et al., 2015). Thus, proper concentration of Mo treatment induces increased the number and weight of nodules in leguminous crops (Hashimoto and Yamasaki, 1976; Rahman et al., 2008; Togay et al., 2008; Alam et al., 2015). In the case of silicon (Si), experiments conducted in cowpea found that application of Si to cowpea promoted nodule formation and function (Nelwamondo and Dakora, 1999). However, whether Si application affects either nodule formation or root morphological traits of soybean plant is not yet known.

$\mathrm{Si}$ is beneficial not only for plant growth but also in conferring tolerance to abiotic and biotic stress (Guntzer et al., 2012; Kim et al., 2014, 2016; Jang et al., 2018). In Japan, slag silicate fertilizer is applied to paddy fields to increase Si uptake of rice plants because of Si-deficient soil (Ma and Takahashi, 2002). Slag is a byproduct of iron production, so it includes various inorganic nutrients, such as $\mathrm{Si}, \mathrm{Fe}, \mathrm{Mo}$, and magnesium (Mg) ( $\mathrm{Ma}$ and Takahashi, 2002). Since Ma et al. (2006) identified Si transfer genes in rice root, similar genes have been discovered in barley, cucumber, tomato, maize, and soybean (Ma et al., 2006; Feng et al., 2009; Mitani et al., 2009; Yamaji et al., 2012; Deshmukh and Bélanger, 2016). Despite the identification of the Si transfer genes (GmNIP2-1 and GmNIP2-2) in soybean roots, the effects of $\mathrm{Si}$ on nodule formation and root morphology in soybean remain unidentified (Deshmukh et al., 2013).

The root system is an essential organ for water acquisition and nutrient absorption throughout a plant's life (Zhao et al., 2017). Moreover, roots participate in nutrient cycling and soil formation/stabilization through interaction with soil organisms (Bardgett et al., 2014; Faucon et al., 2017). Therefore, understanding of root morphological traits helps predict plant growth and development. Information about root system architecture is derived mainly under controlled conditions at early growth stages because manually measuring root traits is time-consuming, laborious, and inaccurate in a fully grown plant (Costa et al., 2001; French et al., 2009; Lobet et al., 2011). In the field, "shovelomics" is a method of field excavation of mature root crowns for analysis of root phenotypes, so shovelomics has been broadly used for breeding and quantitative genetics (Colombi et al., 2015). However, this method measures the ground nodal root (crown root) phenotypes, disregarding the internal root system and the root traits of the younger nodes, despite the overwhelming impact of these roots on plant growth (York and Lynch, 2015). This method of collecting the root data is also time-intensive.

With the advances in data analysis, image-based measurement technologies have become an invaluable detection system for measuring various plant traits, such as leaf color, leaf area index, and stem width and height (York and Lynch, 2015). Several researchers have attempted to identify root traits by highthroughput phenotyping (Leitner et al., 2014; Pace et al., 2014; Lobet et al., 2017). Depending on the target traits, various image analysis methods have been developed, such as X-ray imaging (Mooney et al., 2012), magnetic resonance imaging (MRI; van Dusschoten et al., 2016), 2-dimensional (2D) imaging (Pornaro et al., 2017), and 3-dimensional (3D) imaging (Topp et al., 2013; van Dusschoten et al., 2016). While most of these approaches can analyze root morphological traits, such as length, area, width, and angle, MRI, X-ray, and 3D imaging techniques are difficult to apply in the field because of the associated costs, so 2D image analysis has been widely used (York and Lynch, 2015; Pornaro et al., 2017). For the same reason, the current study used 2D imaging to acquire data on root morphological traits, such as surface area, length, and angle, as well as root nodule number and size in fully grown soybean plants. To analyze morphological traits, we used WinRHIZO technology, which is a root-measuring system. Despite the importance of nodules for $\mathrm{N}$ fixation and $\mathrm{N}$ utilization, there is no simple way to quantify nodules using 2D image analysis under field conditions. For these reasons, nodule number and size were determined by the deep learning-based detection and segmentation for accurate detection.

In this study, we characterized various root traits, including nodule counts and sizes, based on 2D image analysis, to examine the effect of Si fertilization using image analysis with machine learning techniques.

\section{MATERIALS AND METHODS}

\section{Selection of Plant Materials}

Our research team previously identified the proper concentration and uptake ratio of $\mathrm{Si}$, using 15 soybean cultivars (Park et al., 2019). The results confirmed that cv. Taeseon showed a higher absorbed-Si content relative to the other cultivars. Thus, cv. Taeseon was used in the current study to investigate the effect of Si on various phenotypic root traits.

\section{Treatment of Si Fertilizer and Sample Preparation}

The field was located at the Gyeongsang National University Research Farm $\left(35^{\circ} 14^{\prime} \mathrm{N}, 128^{\circ} 09^{\prime} \mathrm{E}\right)$ in Jinju-si, Gyeongnam, South Korea. The experiment was set up as a split-plot arrangement in a randomized complete block design, with three replications. The treatments consisted of (i) Control, (ii) $\mathrm{Si}-$ soil ( $\mathrm{Si}$ applied to soil), and (iii) Si-soil + leaf (Si applied to soil and leaves) since $\mathrm{Si}$ is known to be absorbed via leaves as well (Cao et al., 2020). Each plot size was $4 \mathrm{~m} \times 4 \mathrm{~m}$, with $1 \mathrm{~m}$ row spacing. Before the planting, ridges $(0.3 \mathrm{~m}$ high $\times 0.7 \mathrm{~m}$ wide) were prepared for each plot. Soybean seeds were sown on June 15, 2018, at a planting distance of $0.15 \mathrm{~m}$ using a disk hand planter (TP-10RA, AGRITECNO YAZAKI Co., Ltd., South Korea). For Si soil application, we 
applied $1.6 \mathrm{~kg}$ of commercial silicate fertilizer $\left(25 \% \mathrm{SiO}_{2}-\right.$ $2 \% \mathrm{MgO}-40 \% \mathrm{CaO}$; Pungnong Co., Ltd., South Korea) to the soil surface, according to the manufacturer's recommendations $\left(100 \mathrm{~kg} / 1000 \mathrm{~m}^{2}\right)$, at planting. Additionally, for foliar application of $\mathrm{Si}$ ( $\mathrm{Si}$-soil + leaf), we sprayed $2.0 \mathrm{mM}$ of sodium metasilicate $\left(\mathrm{Na}_{2} \mathrm{SiO}_{3}\right.$; Sigma-Aldrich, United States) when the 4th-5th trifoliate leaf had fully emerged and unrolled (V4-V5 stage). To determine the soil chemical properties in the research area, 20 samples were taken from 0 to $30-\mathrm{cm}$ depth, then air-dried. The soil at the experimental site contained organic matter, available phosphate, $\mathrm{K}, \mathrm{Ca}$, and $\mathrm{Mg}$ at $9.3 \mathrm{~g} / \mathrm{kg}$, $55 \mathrm{mg} / \mathrm{kg}, 0.25 \mathrm{cmol} / \mathrm{kg}, 4.07 \mathrm{cmol} / \mathrm{kg}$, and $0.47 \mathrm{cmol} / \mathrm{kg}$, respectively (Table $\mathbf{1}$ ).

\section{Phenotypic Data Collection Root Sampling and Analysis}

We applied three different Si applications as seen in "Materials and Methods" to identify Si effects on root morphology. We collected 30 root samples from each plot when the soybean plants reached the R8 stage, i.e., when $95 \%$ of the pods display full mature color, and when root growth has ceased (Nleya et al., 2013). Before sampling, the above-ground plant parts were removed, then a circle was marked by a round-basket (30 $\mathrm{cm}$ in diameter) on the soil around the target plant. The target root and soil were carefully removed to a depth of $30 \mathrm{~cm}$. To minimize root and nodule loss, roots were gently washed with tap water which was contained in a basket (width $304 \mathrm{~mm} \times$ height $330 \mathrm{~mm}$ ) to remove attached soil. Weather conditions during the entire soybean growth period is described in Figure 1. The average temperature was $11.8^{\circ} \mathrm{C}$ (October) $-26.9^{\circ} \mathrm{C}$ (July) and the rainfall showed $64.0 \mathrm{~mm}$ (June) $-319.5 \mathrm{~mm}$ (August) (Figure 1).

\section{Image Analysis for Root Phenotype}

Root images were acquired using a mirrorless camera (M100, Canon, Japan) with a mini-rhizobox (Supplementary Figure S1). The camera information is detailed in Supplementary Table S1. All root samples were imaged with the lens focus fixed at $22 \mathrm{~mm}$. Additionally, to measure root morphological traits, the collected root images were analyzed using WinRHIZO Pro software (WinRHIZO, Regent Instruments, Inc., Canada). Each root trait is defined in Supplementary Table S2.

\section{Image Analysis for Nodule Count and Size}

Almost all nodules of soybean roots were small and overlapped each other. The measurements (e.g., number of objects, areas of an object) of small and overlapping objects were computer vision challenges. Therefore, we designed a pipeline of accurate measurements by using a deep network-based nodule segmentation and semi-automatic annotation functionbased error correction process (Figure 2). The pipeline code is available at https://github.com/ektf1130/nodule_in_soybean_ root. The details are provided below.

\section{Training deep network and nodule segmentation}

U-net architecture is a robust package for segmentation of thin and small objects (Olaf et al., 2015). It is a convolutional network architecture for fast and precise segmentation of images known to be the prior best method for segmentation (Livne et al., 2019). Thus, U-net was used for pixel-wise segmentation of soybean root nodules, with separation of the nodules in a soybean root from the background. To train the segmentation network, RGB color images and their mask images are required; the mask image designates the foreground nodules as white and the background as black (Figures 3C,D). U-Net is used mainly to input the image dimension as multiples of 32, and our network used $1024 \times 1024$ pixel images as inputs for maximum resolution considering the specifications of our training computer; Intel(R) Core(TM) i7-4790K CPU @ $4.00 \mathrm{GHz}, 32$ GB RAM, NVIDIA GeForce GTX TITAN X 12 GB.

In the offline process shown as Figure 2, initially, we created 35 masks (annotations) of root images manually using our customized annotation tool. The RGB color and mask images (i.e., training data) were properly scaled and padded for the network size by pre-processing; the original size of RGB and mask images $(6000 \times 4000$ pixels $)$ were converted to $1024 \times 1024$ pixel images (Figures 4A,B). Then, our deep network was trained using the processed training data.

In the online process, input root RGB color images are converted into $1024 \times 1024$ pixel images, and nodule segmentation of the root is performed using the trained deep network; the network outputs mask images.

\section{Post-processing and Nodule measurements}

The fully connected conditional random fields (Krähenbühl and Koltun, 2011) was mainly used to remove noises from mask images (segmentation results) generated by the trained deep network as a post-processing step, to improve the accuracy of segmentation at the pixel level. As a result of the nodule segmentation, the mask image had probabilities of between 0 and 1 for each pixel (Figure 4C). Krähenbühl and Koltun (2011) used the probabilities, and color and position of each pixel to remove noise (Figure 4D). After noise removal, the holes representing nodules in the mask images were filled using the closing process (Figure 4E). Then, the semi-automatic annotation-based error correction was performed. Finally, the fully connected components were detected, and noise was removed by component sizes. The nodules were counted using the detected components (i.e.,

TABLE 1 | Soil chemical properties of the experimental site $(0-30 \mathrm{~cm})$.

\begin{tabular}{lccccccc}
\hline $\mathbf{p H}$ & $\mathbf{E C}$ & $\mathbf{O M}$ & $\mathbf{A v} . \mathbf{P}_{\mathbf{2}} \mathbf{O}_{\mathbf{5}}$ & $\mathbf{K}$ & $\mathbf{C a}$ & $\mathbf{M g}$ & $\mathbf{O R D}$ \\
\hline $1: 5$ & $1: 5(\mathrm{dS} / \mathrm{m})$ & $(\mathrm{g} / \mathrm{kg})$ & $(\mathrm{mg} / \mathrm{kg})$ & & $----(\mathrm{cmol} / \mathrm{kg})$ & ---- & \\
6.65 & 0.21 & 9.3 & 55.0 & $(\mathrm{~kg} / 10 \mathrm{a})$ & 0.25 & 4.07 & 133.00
\end{tabular}



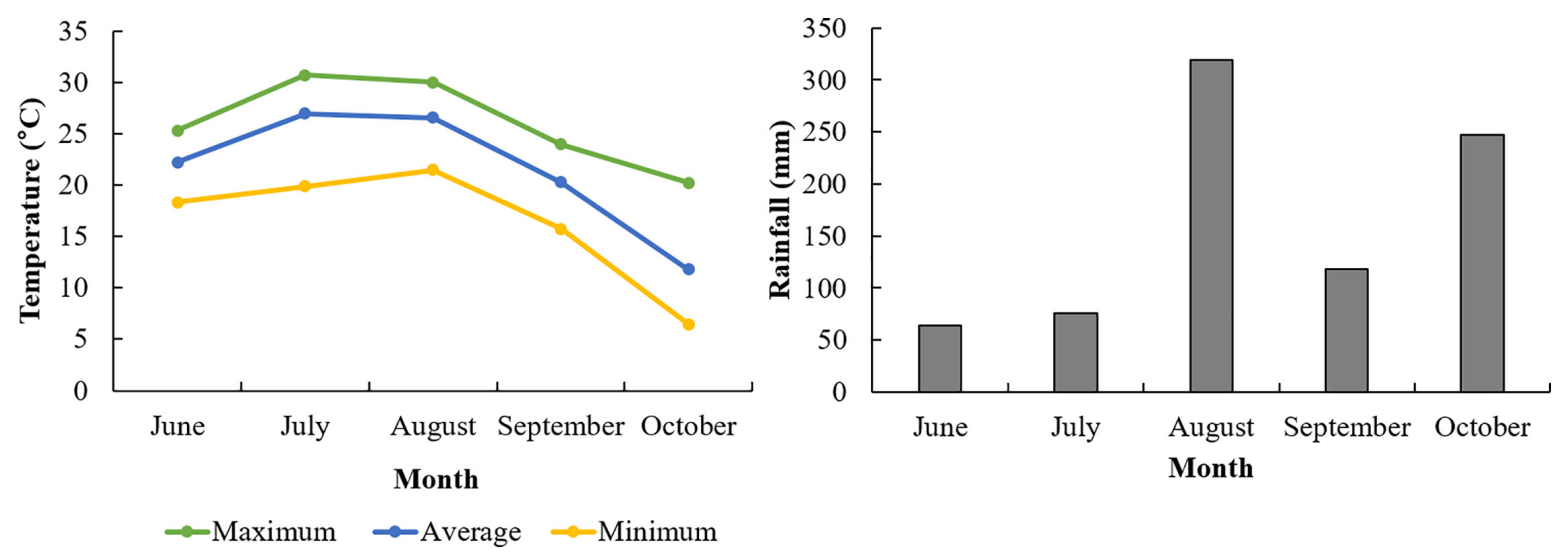

FIGURE 1 | Weather condition of experimental field in 2018.

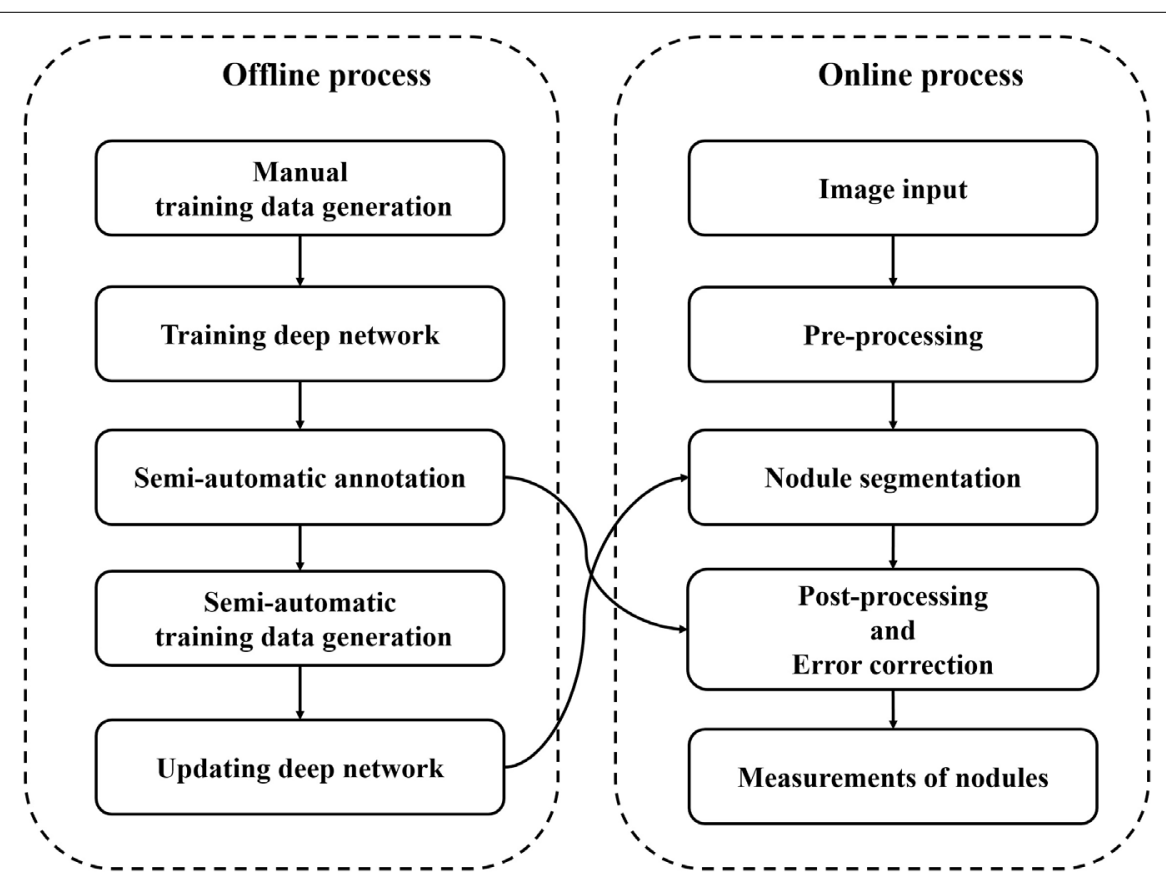

FIGURE 2 | Image analysis pipeline.

blobs), shown in Figure 5D, and the nodule size was converted from pixels to actual size (i.e., $\mathrm{mm}^{2}$ ) using a reference size; the actual sizes of the reference were measured in advance.

\section{Semi-automatic annotation-based error correction and transfer learning}

In general, adding more validated training data increases the performance of the deep learning-based segmentation network and widens the range of data that can be processed. However, generating annotation images (training data) is labor-intensive; it is time-consuming to generate training data because nodules in a root are small and numerous, and the amount of training data required for optimal deep network performance is unknown.
Also, even with the optimal trained networks, segmentation errors can occur for new root images. Therefore, we created a semi-automatic annotation tool to improve the mentioned problem. Our tool was customized based on the existing tool that has a simple to use and convenient graphical user interface (GUI) to generate training data (Dutta et al., 2016). We have added a function that automatically annotates regions of nodules using our pre-trained deep network on the existing tool. Our customized tool was used for semi-automatic annotation (generating training data) and error correction.

Initially, a pre-trained deep network is required for the semiautomatic annotation. So, we manually generated an appropriate amount of training data (mask images) using the customized tool; the appropriate amount means minimal labor for manual 


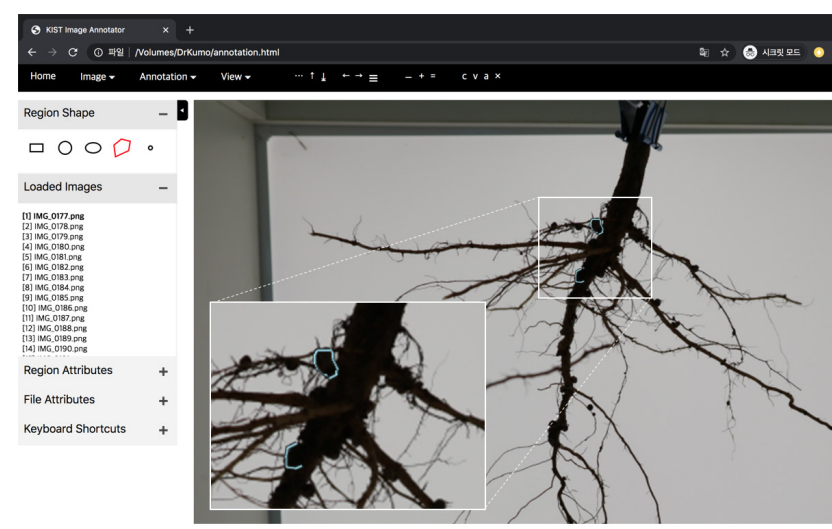

A

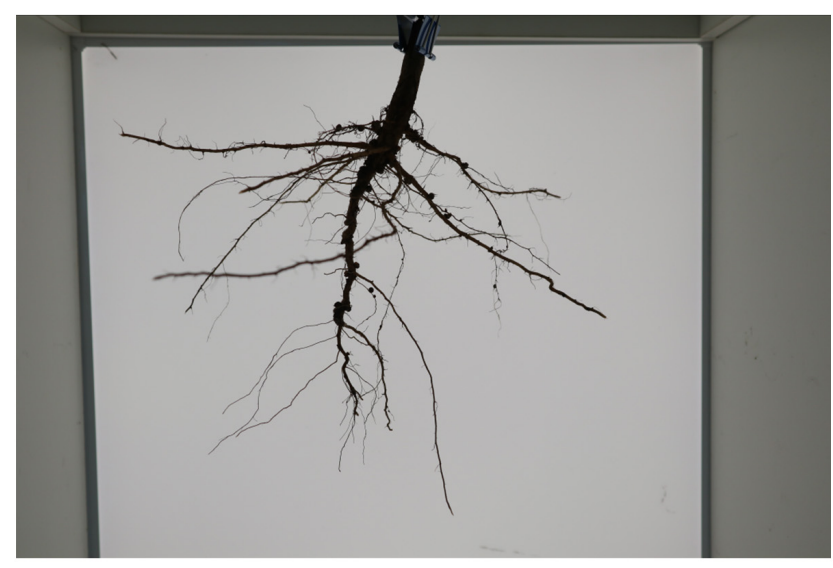

C

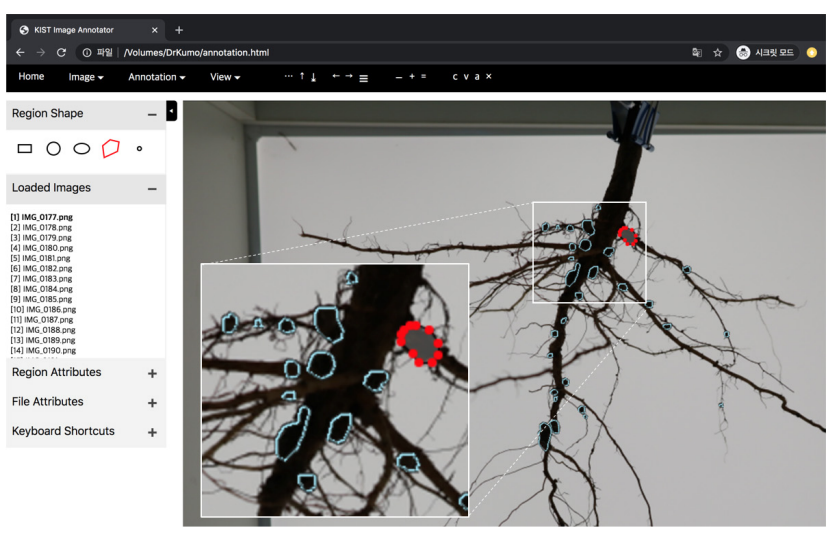

B

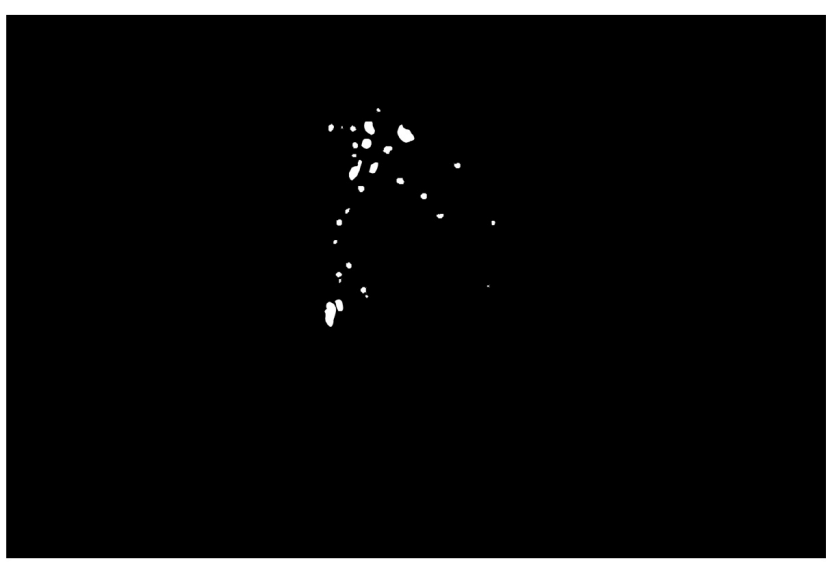

D

FIGURE 3 | Graphical User Interface of annotation tool and training data generation. (A) overview of annotation tool (B) manual inputs of annotation by clicking polygons (C) an RGB color image (D) a mask image.

annotation. We created 35 training data sets of root images manually; there are multiple nodules on each root, and we drew polygons by clicking on the contour of each nodule (Figures 3A,B). Then, a deep network was trained using the training data; it is a pre-trained deep network. The nodule segmentation of the pre-trained deep network was not robust, but it was enough to use as an aid to create additional training data (Supplementary Table S3).

New root images were input into the pre-trained network and mask images were created. Next, the coordinates of contours of each nodule were computed from the mask images, and were then imported into the customized tool and displayed on the new root images (Figures $4 \mathbf{E}, \mathbf{F}$ ). We then manually corrected the error regions of the contours using the GUI tool (Figures $5 \mathbf{A}, \mathbf{B}$ ); the semi-automatic annotation processes significantly reduced the time to create additional training data, which were used to update the pre-trained deep network (i.e., transfer learning). The segmentation performance of each updated pre-trained deep network was improved by incorporating additional training data (Figure 6A). We repeated these processes until the segmentation performance of the updated pre-trained deep network was sufficiently robust. The performance was evaluated using the F1-score metric, which is frequently used to evaluate segmentation performance (Goutte and Gaussier, 2005; Csurka et al., 2013). The F1-score can be used to evaluate our pre-trained network without bias because the score was considered a balance between precision and recall.

$$
\begin{gathered}
\text { Precision }(P)=\frac{T P}{T P+F P} \\
\text { Recall }(R)=\frac{T P}{T P+F N} \\
F 1 \text { score }=2 \times \frac{P \times R}{P+R}
\end{gathered}
$$

True Positive (TP), False Positive (FP), and False Negative (FN) are ratios between the predicted value (nodule and background) from the pre-trained deep network and the actual value (mask images); TP means that the actual foregrounds are predicted as foregrounds by the pre-trained network; FP means that the actual backgrounds are predicted as foregrounds by the network; and FN means that the actual foregrounds are predicted as backgrounds. Finally, the pre-trained deep network using 


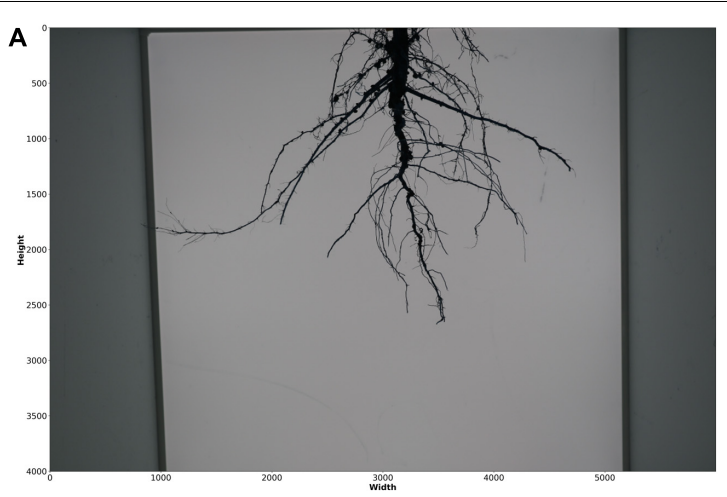

C

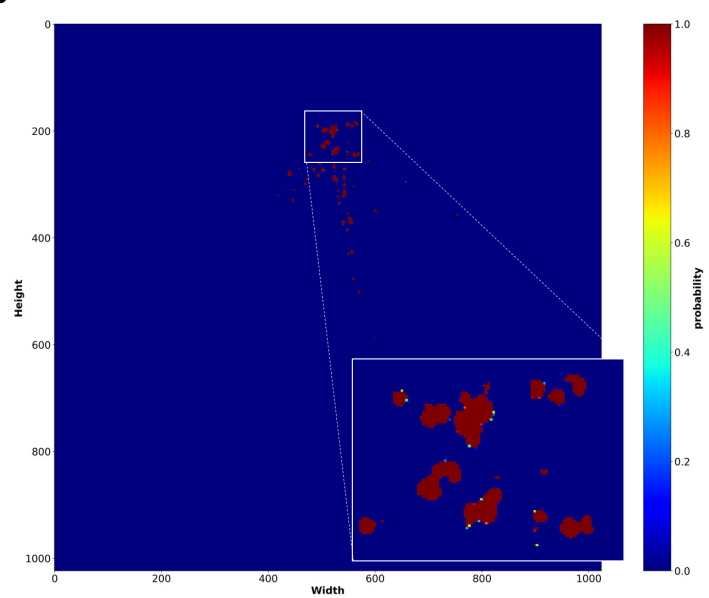

E

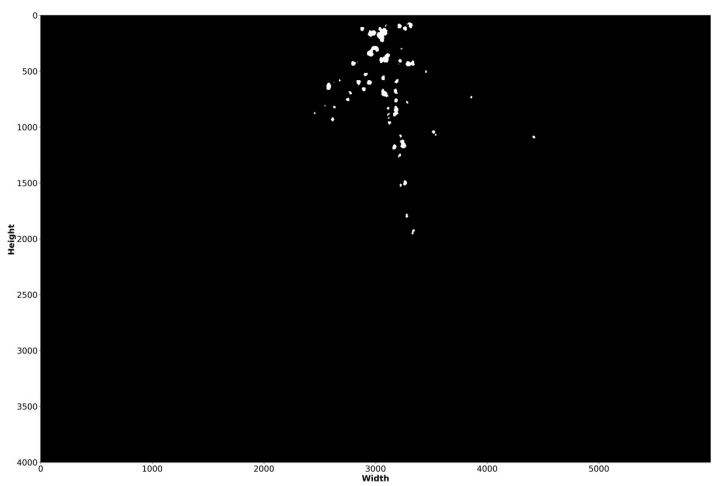

B

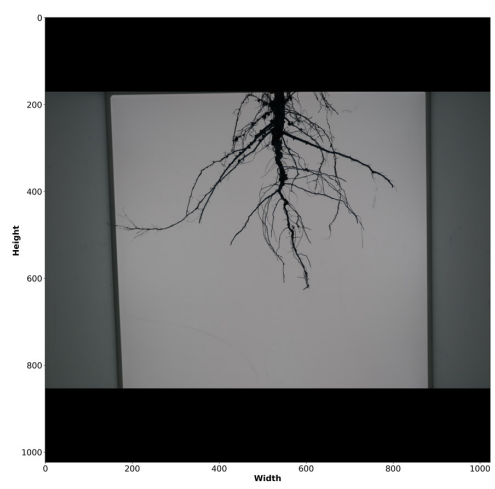

D

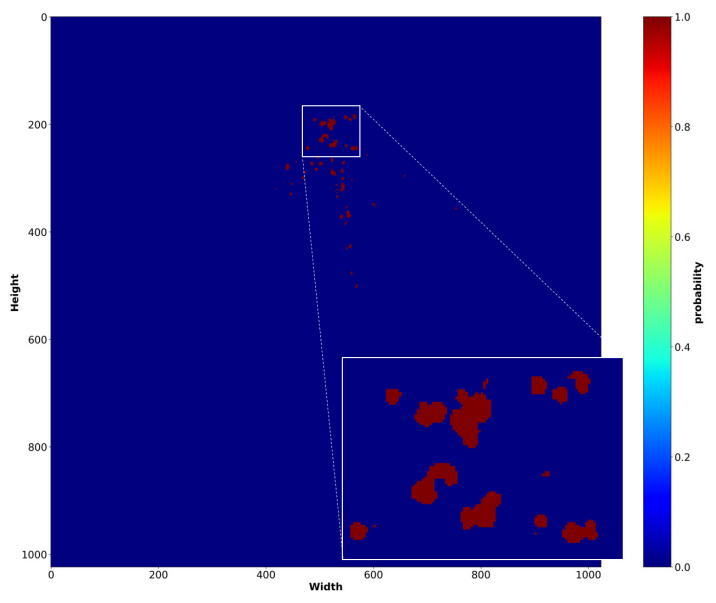

$\mathbf{F}$

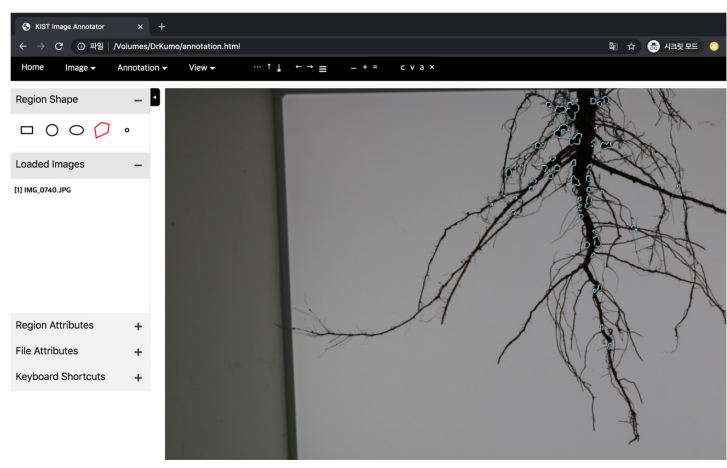

FIGURE 4 | Nodule measurement processes. (A) raw input RGB color image $(6000 \times 4000$ dimensions) (B) pre-processed RGB color image $(1024 \times 1024$ dimensions) (C) segmentation results; probability for each pixel (1024 × 1024 dimensions) (D) post-processing results on segmentation result (1024 $\times 1024$ dimensions) (E) reconstruction of original size (6000 $\times 4000$ dimensions) $(\mathbf{F})$ loading nodule regions on annotation tool; the regions extracted from the final reconstructed segmentation result is displayed on the tool.

135 training data was created and showed robust performance according to the F1-score (Figure 6B).

This pre-trained network became the final nodule segmentation network, with fewer errors than the initial pre-trained network. Additional error correction was performed with the same process as the initial semi-automatic annotation mentioned above. In the online process, error correction was performed on the mask image of the post-processing result, and the new mask was generated after error correction. Nodule measurements were then obtained using the corrected mask images (Figures 5C,D).

\section{Statistical Analysis}

A randomized block design was used with subsampling and three replications (blocks). Three treatments (fertilizer type) were applied randomly within each block. Analysis of variance 

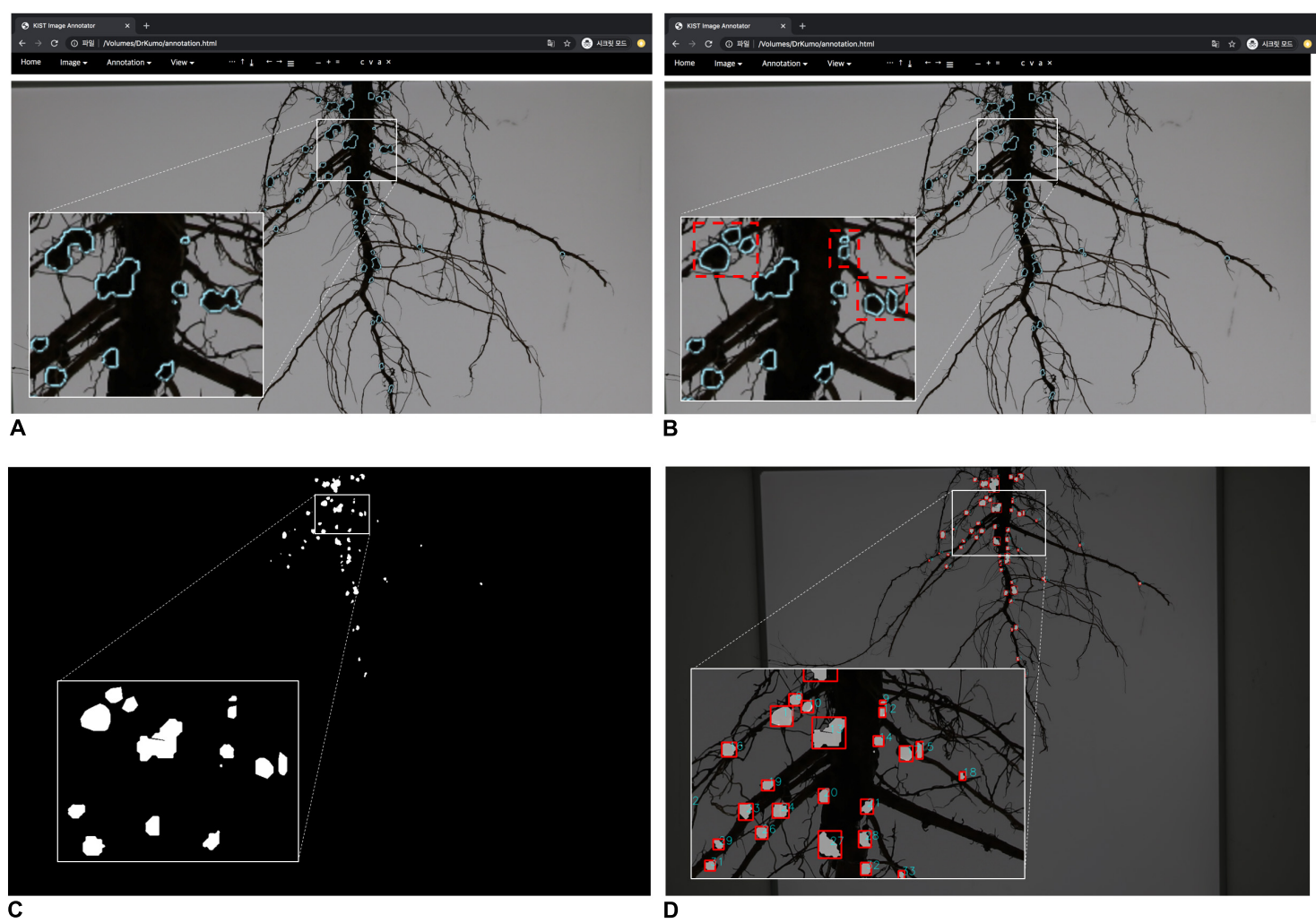

FIGURE 5 | Semi-automatic annotation function-based error correction. (A) confirm of error nodules (B) error correction; red rectangles (C) segmentation result (mask image) before error correction (D) segmentation result after error correction.

\begin{tabular}{|l|l|l|l|l|l|}
\hline & \\
\hline
\end{tabular}

(ANOVA) models were used to investigate the effect of the $\mathrm{Si}$ treatments on the root traits. For these traits, the data tidying consisted of computing the sum of nodule size for each image and converting the area measured in millimeters squared to centimeters squared, resulting in 270 data points. The statistical model is given by:

$$
y_{i j k}=\mu+\beta_{j}+\alpha_{i}+\delta_{i j}+{ }_{i j k}
$$

where $y_{i j k}$ is the response variable (phenotype); $\mu$ is the intercept; $\beta_{j}$ is the $j$-th block effect; $\alpha_{i}$ is the $i$-th treatment effect; $\delta_{i j}$ is the $i j$-th experimental error (plot effect), and ${ }_{i j k} \sim N\left(0, \sigma^{2}\right)$ is the sampling error.

A quantile-quantile plot was performed to verify the null hypothesis of the normality of the residuals, and the fitted versus residuals plot was tested for homogeneity of variance. For some phenotypes (nodule size and count), logarithmic transformation was sufficient to deal with non-normality and heteroscedasticity. 

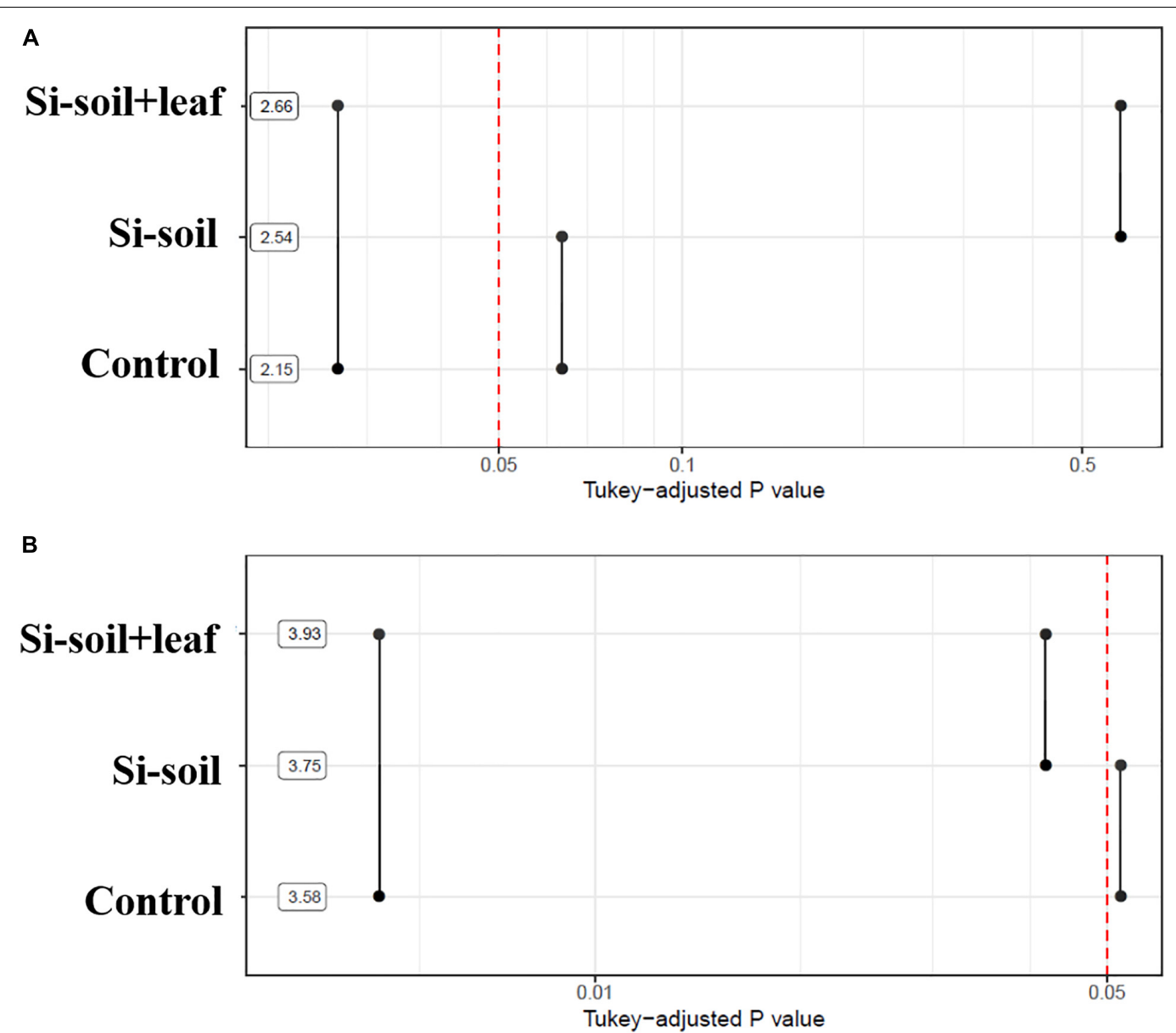

FIGURE 7 $\mid P$-values associated with pairwise comparisons of means of treatments for nodules size (A) and nodules counts (B). Means are shown using a logarithmic scale.

For others, a heteroscedastic linear mixed model was fitted to verify the null hypothesis (i.e., no difference between treatments). The variance structure used to model heteroscedasticity was proportional to the power of the absolute value of the fitted values or different variances across experimental units. Tukey's test was used to compare the means of the treatments. Correlations between root traits in which the treatments were significant, were computed.

\section{RESULTS}

Significant differences in nodule size and number were detected among the treatments (Figure 7). The Si-soil + leaf plants showed a significantly higher mean nodule size as compared with control and Si-soil treated plants. For the number of nodules, the only differences were between $\mathrm{Si}$-soil + leaf and control and between $\mathrm{Si}$-soil and Si-soil + leaf. Overall, Si treatments were effective on increased nodule size and number when applied to both soil and leaf at the same time.

To investigate if the root architecture phenotypes were affected by $\mathrm{Si}$ treatment, nine aspects of root structure were evaluated,
TABLE $2 \mid F$ test for fixed effects from the mixed model fitted to root architecture data originated from a randomized complete block design with subsampling.

\begin{tabular}{lcc}
\hline Variable & F statistics & $\boldsymbol{P}$-value \\
\hline Length & 14.79 & 0.01 \\
Area projection & 4.10 & 0.11 \\
Average diameter & 0.98 & 0.45 \\
Number of tips & 3.44 & 0.14 \\
Number of forks & 14.12 & 0.02 \\
Linked average surface area & 1.32 & 0.36 \\
Linked average diameter & 1.26 & 0.38 \\
Average link angles & 11.80 & 0.02 \\
Main total length & 0.28 & 0.77 \\
\hline
\end{tabular}

including length, average diameter, number of tips, number of forks, projected area, main total length, lateral total length, link projected area, link average length, link average surface area, link average diameter, and link average branching angles (Supplementary Table S2). Among them, three variables, namely length, number of forks, and link average branching angles, showed significant differences (Table 2). This implies that length, 

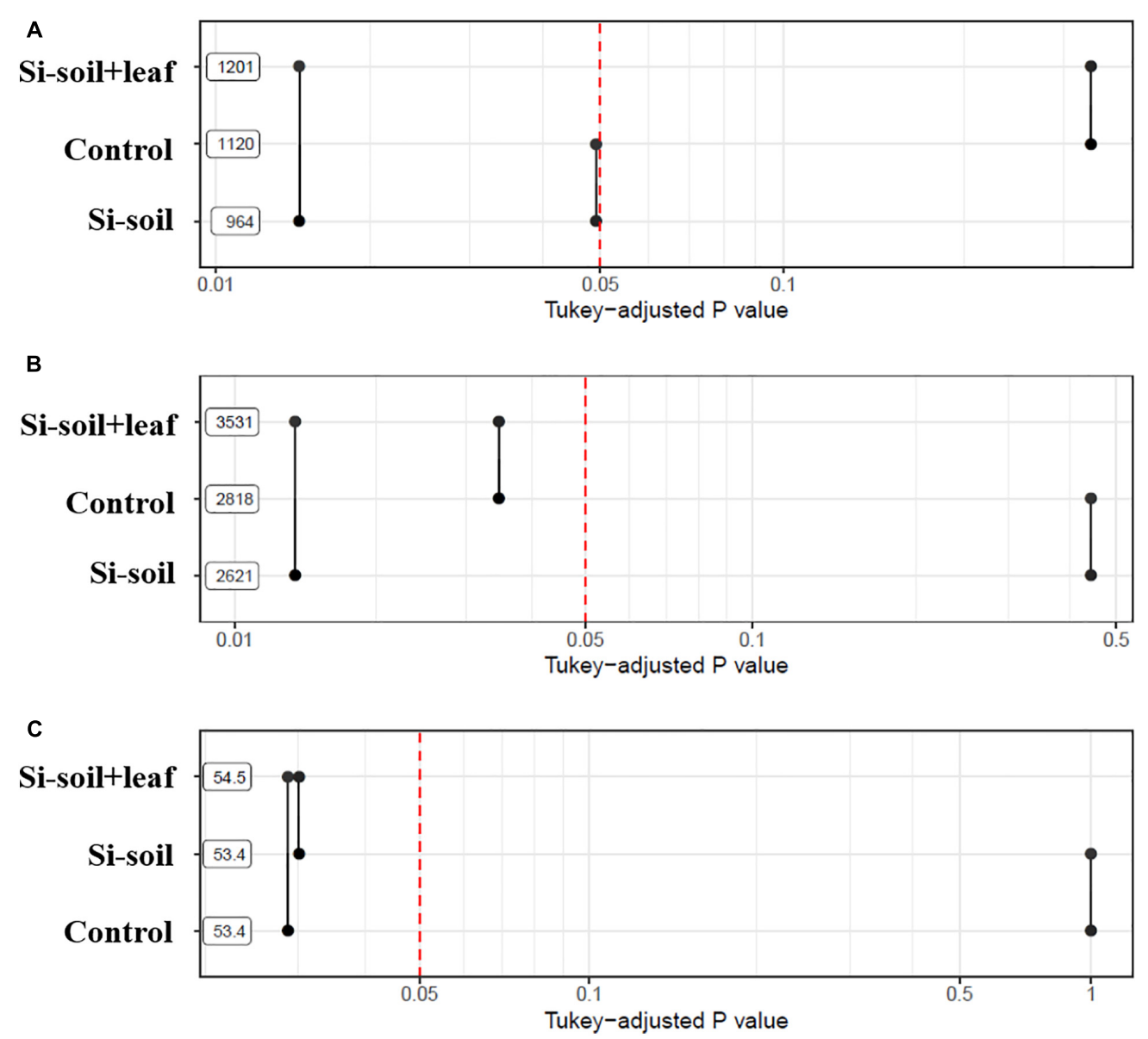

FIGURE 8 | P-values associated with pairwise comparisons of means of treatments for length (A), number of forks (B), and average link angles (C).

TABLE 3 | Correlation network plot between phenotypic data obtained by image analysis and root architecture data.

\begin{tabular}{|c|c|c|c|c|}
\hline & Number of nodules & Root length & Number of forks & Average link angle \\
\hline \multirow[t]{3}{*}{ Nodule size } & ${ }^{\mathrm{a}} 0.95^{\star \star \star}$ & $\mathrm{a} 0.89^{\star \star \star}$ & $\mathrm{a} 0.97^{\star \star \star}$ & ${ }^{a} 0.32^{\star \star}$ \\
\hline & $b_{1} .00^{\star \star}$ & b $0.28^{\star \star}$ & b $0.38^{\star \star \star}$ & ${ }^{b} 0.11$ \\
\hline & ${ }^{c} 0.98^{\star \star}$ & ${ }^{\mathrm{c}} 0.98^{\star \star}$ & ${ }^{\mathrm{c}} 0.99^{\star \star \star}$ & ${ }^{\mathrm{c}} 0.98^{\star \star \star}$ \\
\hline \multirow[t]{3}{*}{ Number of nodules } & 1 & ${ }^{a} 0.99^{\star \star \star}$ & ${ }^{\mathrm{a}} 0.97^{\star \star \star}$ & ${ }^{\mathrm{a}} 0.00$ \\
\hline & & ${ }^{\mathrm{b}} 0.25^{\star}$ & ${ }^{b} 0.35^{\star \star \star}$ & ${ }^{b} 0.08$ \\
\hline & & $c_{1} 1.00^{\star \star \star}$ & $c_{1} 1.00^{\star \star \star}$ & ${ }^{\mathrm{c}} 0.92^{\star \star \star}$ \\
\hline \multirow[t]{3}{*}{ Root length } & & 1 & ${ }^{\mathrm{a}} 0.92^{\star \star \star}$ & $\mathrm{a}-0.14$ \\
\hline & & & ${ }^{b} 0.99^{\star \star \star}$ & ${ }^{b} 0.99^{\star \star}$ \\
\hline & & & ${ }^{c} 1.00^{\star \star \star}$ & ${ }^{\mathrm{c}} 0.92^{\star \star \star}$ \\
\hline \multirow[t]{3}{*}{ Number of forks } & & & 1 & ${ }^{a} 0.26^{\star}$ \\
\hline & & & & ${ }^{\mathrm{b}} 0.96^{\star \star \star}$ \\
\hline & & & & ${ }^{\mathrm{c}} 0.94^{\star \star \star}$ \\
\hline
\end{tabular}

${ }^{a}$ Control.

bSi-soil.

${ }^{c}$ Si-soil + leaf.

${ }^{*},{ }^{* *}$, and ${ }^{* * *}, P<0.05,0.01$, and 0.001 , respectively.

the number of forks, and average link angles are important morphological traits for Si response in soybean root. Length showed significant difference between Si-soil and control, and between control and Si-soil + leaf (Figure 8A). However, our results did not show significant difference between $\mathrm{Si}$-soil and control in number of forks, while a significant difference observed 
in comparison with control and $\mathrm{Si}$-soil + leaf, and between $\mathrm{Si}-$ soil and Si-soil + leaf (Figure 8B). Link branching angle observed similar pattern with number of forks. Except for comparison with control and Si-soil, all treatment showed significant difference at $P<0.05$ (Figure 8C). Those three root traits were then correlated with the nodule size and number of nodules formed in the control and treated plants to determine if the root structure phenotypes affected nodule formation (Table 3). Treatments do not have effects between nodule size and the number of nodules and between root length and the number of forks. However, there were high correlations $(r=0.95-1.00)$ between nodule size and number in the control and all treatments, indicating that nodule size and number are highly associated, irrespective of the amount of Si the plant absorbs. There were also high correlations ( $r=0.92-1.00)$ between number of forks and length in the control and all treatments, suggesting that fork development, as the initiation point of elongation of lateral roots, augments root length at all Si levels. There were significant Si treatment effects on the correlation between average branching angle and root length and between average branching angle and number of forks, with correlation values ranging from $r=0.92$ to $r=0.99$, showing that $\mathrm{Si}$ is responsible for lateral root formation and its angle. The correlation between nodule size and between average branching angle and between nodule number and average branching angle was highly affected only by the Si-soil + leaf, although there was a low correlation $(r=0.32)$ between nodule size and average branching angle in the control plants. However, the correlation results between nodule size and root length, between nodule size and number of forks, between nodule number and root length, and between nodule number and number of forks were difficult to interpret because the correlations were high both in the control and in the Si treatment on Si-soil + leaf treatment, while the correlation was low in the Si-soil treatment.

\section{DISCUSSION}

The image was obtained to maximize the area of roots by adjusting the camera angle. Nonetheless, it is impossible to characterize the nodule behind the roots image taken for this experiment. However, it is still analyzable because all treatments including the control had the same method for image obtaining. In other words, if one image has error, the others would have same error. And this is why a lot of images were taken replications

TABLE 4 | Analysis of variance from randomized complete blocks design with subsampling for nodule size $\left(\mathrm{mm}^{2}\right)$ and nodule counts.

\begin{tabular}{lcc}
\hline Source & \multicolumn{2}{c}{ Mean square } \\
\cline { 2 - 3 } & Nodule size & Nodule number \\
\hline Blocks & $16.49^{* \star}$ & $22.01^{\star * \star}$ \\
Treatments & $6.28^{*}$ & $2.75^{* \star}$ \\
Experimental error & 0.61 & 0.10 \\
Sampling error & 0.21 & 0.15 \\
* $^{* *}$, and ${ }^{* * *}, P<0.05,0.01$, and 0.001, respectively.
\end{tabular}

to reduce error. Considering this, the high contrast image was fine to characterize nodule. The way the nodule was characterized was to detect the bumpy area from linear line of roots. Based on this, the nodule was found and counted. Once nodule was detected, the part of circle could be detected. Then, based on this part of circle, the rest of the nodule was inferred. According to our results, Si treated soybean plant showed increased nodule number and nodule size as compared to non-Si treated soybean plant. This result revealed that $\mathrm{Si}$ treatment induces or participates nodule formation. We assumed that the reason seems to several reasons. The first hypothesis is that $\mathrm{Si}$ application is responsible for ABA accumulation, which, in turn, causes lateral root formation and growth, increasing the number of infection sites for nodulation. Furthermore, the increased root angle associated with Si treatment was highly correlated with nodule formation. It may worth to investigate if it is true or not by measuring ABA in the future.

The second hypothesis is that $\mathrm{Si}$ influence on the expression of nod genes which affect to formation of nodules in leguminous plants (Nelwamondo and Dakora, 1999). Furthermore, Si is involved in synthesis of isoflavonoids, thus application of Si fertilizer into soil induces increased nodule formation of leguminous plants (van Bockhaven et al., 2013). Because, leguminous plants release isoflavonoids for enticing nitrogenfixing bacteria (Eckardt, 2006).

$\mathrm{Si}$ is known to increase nodule formation and to elongate root length in legumes, which increases the number of potential sites for infection by rhizobial invasion (Nelwamondo and Dakora, 1999). Accordingly, the results in the current study were consistent with the findings of Nelwamondo and Dakora (1999). Root length was highly correlated with nodule size and number in the current study. Furthermore, Si seems to be involved with the total number of secondary roots as forks (Guo et al., 2006). We assumed that this phenomenon also was due to the accumulation of abscisic acid (ABA) in roots, as a result of the Si treatment (Signora et al., 2001; Dakora and Nelwamondo, 2003). According to this study, ABA accumulation, due to Si application, influences not only root growth but also lateral root development and growth. Liang and Harris (2005) likewise reported that ABA stimulates lateral root formation in legumes.

In addition, lateral root formation increases as the concentration of ABA increases (Liang and Harris, 2005). Previously, nodule number was responsive to $\mathrm{Si}$ supply in legumes (Nelwamondo and Dakora, 1999) because secondary root formation is highly responsive to the Si concentration (Guo et al., 2006). Together, these observations could explain why Si-soil + leaf treatment showed a stronger correlation than $\mathrm{Si}$-soil. In other words, the Si concentration may not be sufficient to be influential to lateral root formation. Thus, it would be worthwhile to investigate the optimal concentration of Si for nodulation and each of the root morphological traits.

Nodules at a depth of $20 \mathrm{~cm}$ or greater were frequently observed at different sites in different cultivars (Grubinger et al., 1982). However, the number of nodules varied significantly in the vertical distribution, depending on the cultivar. If a certain depth is advantageous for nodule formation, the root structure could be influential to nodule formation as well. In the current study, the 
Si treatment was highly correlated with a higher root angle, which means that Si was involved with root formation horizontally, near the soil surface, and consequently, there was more nodule formation near the soil surface. This result might indicate that the cultivar and bacteria used in this study were a lot more influential in promoting nodule formation in the near soil surface.

The reason for the high correlations between nodule size and root length, between nodule size and forks number, between nodule number and root length, and between nodule number and forks number in both the control and Si-soil + leaf but low correlations for $\mathrm{Si}$-soil could be because of the huge variation found in the data set in the current study (Table 4). There are very significant differences among blocks for nodule size and the number of nodules, which are larger effects than those among treatments. Consequently, it is hard to detect clear difference. This could be because soybean plants are very susceptible to various abiotic stresses (Board, 2013). It may be enhanced with more sophisticated experimental design.

The robust measurements in the current study using the emerging, deep learning-based detection and segmentation (Olaf et al., 2015; Ren et al., 2017; Chen et al., 2018; Feng et al., 2020; Gao et al., 2020) allowed distinct separation of the object from the background, unlike the conventional image processing methods, which are not robust to various types of objects and noises (Khan et al., 2010; Wang et al., 2011). Overall, the image analysis using machine learning in the current study enabled us to characterize numerous nodules in roots in many plants, which is truly huge advance.

\section{CONCLUSION}

Using 2D images, we analyzed huge number of soybean root nodule by machine learning technology. Thus we identified $\mathrm{Si}$ application induce increase of nodule size and number. However, current results cannot prove the accurate mechanism. We assumed two possibility. The first hypothesis is that $\mathrm{Si}$ application accumulate hormone ABA thus, this phenomena induce various root responses such as nodule formation and root architecture. The second hypothesis is that Si treatment not only stimulate nod gene but also increase isoflavonoid contents, consequently, increased nodule number and size occurs. To prove those hypothesis, additional experiments are required.

\section{REFERENCES}

Alam, F., Kim, T. Y., Kim, S. Y., Alam, S., Pramanik, P., Kim, P. J., et al. (2015). Effect of molybdenum on nodulation, plant yield and nitrogen uptake in hairy vetch (Vicia villosa Roth). Soil Sci. Plant Nutr. 61, 664-675. doi: 10.1080/ 00380768.2015.1030690

Armah, P., Archer, A., and Phillips, G. C. (2011). Drivers Leading to Higher Food Prices: Biofuels are not the Main Factor: Biofuels. New York, NY: Springer, 19-36. doi: 10.1007/s11627-009-9211-0

Bardgett, R. D., Mommer, L., and Vries, F. T. (2014). Going underground: root traits as drivers of ecosystem processes. Trends Ecol. Evol. 29, 692-699. doi: 10.1016/j.tree.2014.10.006

Bellaloui, N., Hu, Y., Mengistu, A., Kassem, M. A., and Abel, C. A. (2013). Effects of foliar boron application on seed composition, cell wall boron, and seed d15N
Furthermore, comparative experiments are need for confirming the utility of nodule baseline technology in leguminous plants. If we get reasonable result, we will open website to use those technology to other researcher.

\section{DATA AVAILABILITY STATEMENT}

The datasets generated for this study are available on request to the corresponding author.

\section{AUTHOR CONTRIBUTIONS}

YC and SH wrote the manuscript and analyzed the data. UL participated in deep learning analysis. RS statistically analyzed the data. C-IN assisted with the data and sample collection. YK inspected the experimental design and revised the manuscript. All authors contributed to the article and approved the submitted version.

\section{FUNDING}

This research was supported by the Basic Science Research Program through the National Research Foundation of Korea (NRF) funded by the Ministry of Education (2017R1D1A3B03030917 and 2019R1A6A1A11052070).

\section{SUPPLEMENTARY MATERIAL}

The Supplementary Material for this article can be found online at: https://www.frontiersin.org/articles/10.3389/fpls.2020. 520161/full\#supplementary-material

Supplementary Figure 1 | Mini-rhizobox for image acquisition.

Supplementary Table 1 | Camera specifications.

Supplementary Table 2 | Short description of the parameters analyzed in the study using WinRHIZO root analysis software (Regent Instruments, Canada).

Supplementary Table 3 | Training result of nodule size and number of nodule. Deep network was trained using 35 training data set and then, the test was conducted by using 200 root images.

and d13C isotopes in water-stressed soybean plants. Front. Plant Sci. 4:270. doi: $10.3389 /$ fpls.2013.00270

Bharati, M. P., Whigham, D. K., and Voss, R. D. (1986). Soybean response to tillage and nitrogen, phosphorus, and potassium fertilization 1. J. Agron. 78, 947-950. doi: 10.2134/agronj1986.00021962007800060002x

Bloom, A. J. (2015). The increasing importance of distinguishing among plant nitrogen sources. Curr. Opin. Plant Biol. 25, 10-16. doi: 10.1016/j.pbi.2015.03. 002

Board, J. (2013). A Comprehensive Survey of International Soybean Research: Genetics, Physiology, Agronomy and Nitrogen Relationships. London: IntechOpen. doi: 10.5772/5264

Brear, E. M., Day, D. A., and Smith, P. M. C. (2013). Iron: an essential micronutrient for the legume-rhizobium symbiosis. Front. Plant Sci. 4:359. doi: 10.3389/fpls. 2013.00359 
Cao, B. L., Ma, Q., and Xu, K. (2020). Silicon restrains drought-induced ROS accumulation by promoting energy dissipation in leaves of tomato. Protoplasma 257, 537-547. doi: 10.1007/s00709-019-01449-0

Chen, L., Papandreou, G., Kokkinos, I., Murphy, K., and Yuille, A. L. (2018). DeepLab: semantic image segmentation with deep convolutional nets, atrous convolution, and fully connected CRFs. IEEE Trans. Pattern Anal. Mach. Intell. 40, 834-848. doi: 10.1109/TPAMI.2017.2699184

Colombi, T., Kirchgessner, N., Le Marié, C. A., York, L. M., Lynch, J. P., and Hund, A. (2015). Next generation shovelomics: set up a tent and REST. Plant Soil 388, 1-20. doi: 10.1007/s11104-015-2379-7

Costa, C., Dwyer, L. M., Hamel, C., Muamba, D. F., Wang, X. L., Nantais, L., et al. (2001). Root contrast enhancement for measurement with optical scanner-based image analysis. Can. J. Bot. 79, 23-29. doi: 10.1139/b00-142

Csurka, G., Larlus, D., Perronnin, F., and Meylan, F. (2013). What is a good evaluation measure for semantic segmentation? BMVC 27:2013. doi: 10.5244/ C. 27.32

Dakora, F. D., and Nelwamondo, A. (2003). Silicon nutrition promotes root growth and tissue mechanical strength in symbiotic cowpea. Funct. Plant Biol. 30, 947-953. doi: 10.1071/FP02161

Deshmukh, R., and Bélanger, R. R. (2016). Molecular evolution of auaporins and silicon influx in plants. Funct. Ecol. 30, 1277-1285. doi: 10.1111/1365-2435. 12570

Deshmukh, R. K., Vivancos, J., Guérin, V., Sonah, H., Labbé, C., Belzile, F., et al. (2013). Identification and functional characterization of silicon transporters in soybean using comparative genomics of major intrinsic proteins in Arabidopsis and rice. Plant Mol. Biol. 83, 303-315. doi: 10.1007/s11103-013-0087-3

Dutta, A., Gupta, A., and Zissermann, A. (2016). VGG Image Annotator (VIA). Available online at: http://www.robots.ox.ac.uk/ vgg/software/via/. (accessed May 10, 2018).

Eckardt, N. A. (2006). The role of flavonoids in root nodule development and auxin transport in Medicago truncatula. Plant Cell 18, 1539-1540. doi: 10.1105/tpc. 106.044768

Faucon, M. P., Houben, D., and Lambers, H. (2017). Plant functional traits: soil and ecosystem services. Trends Plant Sci. 22, 385-394. doi: 10.1016/j.tplants. 2017.01.005

Feng, J., Shi, Q., and Wang, X. (2009). Effects of exogenous silicon on photosynthetic capacity and antioxidant enzyme activities in chloroplast of cucumber seedlings under excess manganese. Agric. Sci. China 8, 40-50. doi: 10.1016/S1671-2927(09)60007-9

Feng, X., Zhan, Y., Wang, Q., Yang, X., Yu, C., Wang, H., et al. (2020). Hyperspectral imaging combined with machine learning as a tool to obtain high-throughput plant salt-stress phenotyping. Plant J. 101, 1448-1461. doi: $10.1111 /$ tpj.14597

French, A., Ubeda-Tomás, S., Holman, T. J., Bennett, M. J., and Pridmore, T. (2009). High-throughput quantification of root growth using a novel imageanalysis tool. Plant Physiol. 150, 1784-1795. doi: 10.1104/pp.109.140558

Gao, Z., Luo, Z., Zhang, W., Lv, Z., and Xu, Y. (2020). Deep learning application in plant stress imaging: a review. AgriEngineering. 2, 430-446. doi: 10.3390/ agriengineering2030029

Goutte, C., and Gaussier, E. (2005). "A probabilistic interpretation of precision, recall and F-score, with implication for evaluation," in Advances in Information Retrieval. ECIR. Lecture Notes in Computer Science, Vol. 3408, eds D. E. Losada and J. M. Fernández-Luna (Berlin: Springer). doi: 10.1007/978-3-540-31 865-1_25

Grubinger, V., Zobel, R., Vendeland, J., and Cortes, P. (1982). Nodule distribution on roots of field-grown soybeans in subsurface soil horizons 1. Crop Sci. 22, 153-155. doi: 10.2135/cropsci1982.0011183X002200010036x

Guntzer, F., Keller, C., and Meunier, J. D. (2012). Benefits of plant silicon for crops: a review. Agron. Sustain. Dev. 32, 201-213. doi: 10.1007/s13593-011-0039-8

Guo, Z. G., Liu, H. X., Tian, F. P., Zhang, Z. H., and Wang, S. M. (2006). Effect of silicon on the morphology of shoots and roots of alfalfa (Medicago sativa). Aust. J. Exp. Agric. 46, 1161-1166. doi: 10.1071/EA05117

Hashimoto, K., and Yamasaki, S. I. (1976). Effects of molybdenum application on the yield, nitrogen nutrition and nodule development of soybeans. J. Soil Sci. Plant Nutr. 22, 435-443. doi: 10.1080/00380768.1976.10433005

He, F. J., and Chen, J. Q. (2013). Consumption of soybean, soy foods, soy isoflavones and breast cancer incidence: differences between Chinese women and women in western countries and possible mechanisms. Food Sci. Hum. Well. 2, 146-161. doi: 10.1016/j.fshw.2013.08.002

Jang, S. W., Kim, Y., Khan, A. L., Na, C. I., and Lee, I. J. (2018). Exogenous short-term silicon application regulates macro-nutrients, endogenous phytohormones, and protein expression in Oryza sativa L. BMC Plant Biol. 18:4. doi: 10.1186/s12870-017-1216-y

Khan, R., Hanbury, A., and Stoettinger, J. (2010). "Skin detection: a random forest approach," in Proceedings of the IEEE International Conference on Image Processing, September 26-29, Hong Kong, 4613-4616. doi: 10.1109/ICIP.2010. 5651638

Kim, Y. H., Khan, A. L., Kim, D. H., Lee, S. Y., Kim, K. M., Waqas, M., et al. (2014). Silicon mitigates heavy metal stress by regulating P-type heavy metal ATPases, Oryza sativa low silicon genes, and endogenous phytohormones. BMC Plant Biol. 14:13. doi: 10.1186/1471-2229-14-13

Kim, Y. H., Khan, A. L., and Lee, I. J. (2016). Silicon: a duo synergy for regulating crop growth and hormonal signaling under abiotic stress conditions. Crit. Rev. Biotechnol. 36, 1099-1109. doi: 10.3109/07388551.2015.1084265

Krähenbühl, P., and Koltun, V. (2011). Efficient inference in fully connected crfs with gaussian edge potentials. Adv. Neural Inform. Process. Syst. 24, 109-117.

Leitner, D., Felderer, B., Vontobel, P., and Schnepf, A. (2014). Recovering root system traits using image analysis exemplified by two-dimensional neutron radiography images of lupine. Plant Physiol. 164, 24-35. doi: 10.1104/pp.113. 227892

Liang, Y., and Harris, J. M. (2005). Response of root branching to abscisic acid is correlated with nodule formation both in legumes and nonlegumes. Am. J. Bot. 92, 1675-1683. doi: 10.3732/ajb.92.10.1675

Livne, M., Rieger, J., Aydin, O. U., Taha, A. A., Akay, E. M., Kossen, T., et al. (2019). A U-Net deep learning framework for high performance vessel segmentation in patients with cerebrovascular disease. Front. Neurosci. 13:97. doi: 10.3389/fninf. 2019.00030

Lobet, G., Koevoets, I. T., Noll, M., Meyer, P. E., Tocquin, P., and Périlleux, C. (2017). Using a structural root system model to evaluate and improve the accuracy of root image analysis pipelines. Front. Plant Sci. 8:447. doi: 10.3389/ fpls.2017.00447

Lobet, G., Pagès, L., and Draye, X. (2011). A novel image-analysis toolbox enabling quantitative analysis of root system architecture. Plant Physiol 157, 29-39. doi: $10.1104 /$ pp.111.179895

Ma, J. F., and Takahashi, E. (2002). Soil, Fertilizer, and Plant Silicon Research in Japan. Amsterdam: Elsevier Science B.V.

Ma, J. F., Tamai, K., Yamaji, N., Mitani, N., Konishi, S., Katsuhara, M., et al. (2006). Silicon transporter in rice. Nature 440, 688-691. doi: 10.1038/nature04590

Masclaux-Daubresse, C., Daniel-Vedele, F., Dechorgnat, J., Chardon, F., Gaufichon, L., and Suzuki, A. (2010). Nitrogen uptake, assimilation and remobilization in plants: challenges for sustainable and productive agriculture. Ann. Bot. 105, 1141-1157. doi: 10.1093/aob/mcq028

Mendel, R. R., and Hänsch, R. (2002). Molybdoenzymes and molybdenum cofactor in plants. J. Exp. Bot. 53, 1689-1698. doi: 10.1093/jxb/ erf038

Mitani, N., Chiba, Y., Yamaji, N., and Ma, J. F. (2009). Identification and characterization of maize and barley Lsi2-like silicon efflux transporters reveals a distinct silicon uptake system from that in rice. Plant Cell 21, 2133-2142. doi: 10.1105/tpc.109.067884

Mooney, S. J., Pridmore, T. P., Helliwell, J., and Bennett, M. J. (2012). Developing X-ray computed tomography to non-invasively image 3-D root systems architecture in soil. Plant Soil 352, 1-22. doi: 10.1007/s11104-0111039-9

Nelwamondo, A., and Dakora, F. D. (1999). Silicon promotes nodule formation and nodule function in symbiotic cowpea (Vigna unguiculata). New Phytol. 142, 463-467. doi: 10.1046/j.1469-8137.1999.00409.x

Nleya, T., Sexton, P., Gustafson, K., and Miller, J. M. (2013). "Soybean growth stages," in IGrow Soybean: Best Management Practices for Soybean Production, eds D. E. Clay, C. G. Carlson, S. A. Clay, L. Wagner, D. Deneke, and C. Hay (Brookings, SD: South Dakota State University, SDSU Extension).

Olaf, R., Philipp, F., and Thomas, B. (2015). "U-Net: convolutional networks for biomedical image segmentation," in Proceedings of the International Conference on Medical Image Computing and Computer-Assisted Intervention, (Cham: Springer), 234-241. doi: 10.1007/978-3-319-24574-4_28 
Pace, J., Lee, N., Naik, H. S., Ganapathysubramanian, B., and Lübberstedt, T. (2014). Analysis of maize (Zea mays L.) seedling roots with the highthroughput image analysis tool ARIA (Automatic Root Image Analysis). PLoS One 24:e108255. doi: 10.1371/journal.pone.0108255

Park, Y. G., Park, S. M., Na, C. I., and Kim, Y. (2019). Identification of optimal concentration of silicon application and its roles in uptake of essential nutrients in soybean (Glycine max L.). J. Crop Sci. Biotechnol. 22, 1-10. doi: 10.1007/ s12892-018-0266-0

Pornaro, C., Macolino, S., Menegon, A., and Richardson, R. (2017). WinRHIZO technology for measuring morphological traits of bermudagrass stolons. Agron. J. 109, 3007-3010. doi: 10.2134/agronj2017.03.0187

Rahman, M. M., Bhuiyan, M. M. H., Sutradhar, G. N. C., Rahman, M. M., and Paul, A. K. (2008). Effect of phosphorus, molybdenum and rhizobium inoculation on yield and yield attributes of mungbean. Int. J. Sustain. Crop Prod. 3, 26-33. doi: 10.11648/j.ajaf.20190703.14

Ren, S., He, K., Girshick, R., and Sun, J. (2017). Faster R-CNN: towards realtime object detection with region proposal networks. IEEE Trans. Pattern Anal. Mach. Intell. 39, 1137-1149. doi: 10.1109/TPAMI.2016.2577031

Rentsch, D., Schmidt, S., and Tegeder, M. (2007). Transporters for uptake and allocation of organic nitrogen compounds in plants. FEBS Lett. 581, 2281-2289. doi: 10.1016/j.febslet.2007.04.013

Schultze, M., and Kondorosi, A. (1998). Regulation of symbiotic root nodule development. Ann. Rev Genet. 32, 33-57. doi: 10.1104/pp.124.2.531

Signora, L., De Smet, I., Foyer, C. H., and Zhang, H. (2001). ABA plays a central role in mediating the regulatory effects of nitrate on root branching in Arabidopsis. Plant J. 28, 655-662. doi: 10.1046/j.1365-313x.2001.01185.x

Smith, F. W. (1982). "Mineral nutrition of legumes", in Nitrogen Fixation in Legumes, ed. J. M. Vincent (Sydney, NSW: Academic Press), 155-172. doi: 10.1007/978-94-009-1387-5_29

Stougaard, J. (2000). Regulators and regulation of legume root nodule development. Plant Physiol. 124, 531-540.

Tegeder, M., and Masclaux-Daubresse, C. (2018). Source and sink mechanisms of nitrogen transport and use. New Phytol. 217, 35-53. doi: 10.1111/nph.14876

Togay, Y., Togay, N., and Dogan, Y. (2008). Research on the effect of phosphorus and molybdenum applications on the yield and yield parameters in lentil (Lens culinaris Medic.). Afr. J. Biotechnol. 7, 1256-1260. doi: 10.5958/0976-0571.2015. 00120.4
Topp, C. N., Iyer-Pascuzzi, A. S., Anderson, J. T., Lee, C. R., Zurek, P. R., Symonova, O., et al. (2013). 3D phenotyping and quantitative trait locus mapping identify core regions of the rice genome controlling root architecture. Proc. Natl. Acad. Sci. U.S.A. 110, E1695-E1704. doi: 10.1073/pnas.1304354110

van Bockhaven, J., De Vleesschauwer, D., and Höfte, M. (2013). Towards establishing broad-spectrum disease resistance in plants: silicon leads the way. J. Exp. Bot. 64, 1281-1293. doi: 10.1093/jxb/ers329

van Dusschoten, D., Metzner, R., Kochs, J., Postma, J. A., Pflugfelder, D., Bühler, J., et al. (2016). Quantitative 3D analysis of plant roots growing in soil using magnetic resonance imaging. Plant Physiol. 170, 1176-1188. doi: 10.1104/pp. 15.01388

Wang, X. Y., Wang, T., and Bu, J. (2011). Color image segmentation using pixel wise support vector machine classification. Pattern Recognit. 44, 777-787. doi: 10.1016/j.patcog.2010.08.008

Yamaji, N., Chiba, Y., Mitani-Ueno, N., and Ma, J. F. (2012). Functional characterization of a silicon transporter gene implicated in silicon distribution in barley. Plant Physiol. 160, 1491-1497. doi: 10.1104/pp.112.20 4578

York, L. M., and Lynch, J. P. (2015). Intensive field phenotyping of maize (Zea may L.) root crowns identifies phenes and phene integration associated with plant growth and nitrogen acquisition. J. Exp. Bot. 66, 5493-5505. doi: 10.1093/jxb/ erv241

Zhao, J., Bodner, G., Rewald, B., Leitner, D., Nagel, K. A., and Nakhforoosh, A. (2017). Root architecture simulation improves the inference from seedling root phenotyping towards mature root systems. J. Exp. Bot. 68, 965-982. doi: $10.1093 /$ jxb/erw494

Conflict of Interest: The authors declare that the research was conducted in the absence of any commercial or financial relationships that could be construed as a potential conflict of interest.

Copyright $\odot 2020$ Chung, Lee, Heo, Silva, Na and Kim. This is an open-access article distributed under the terms of the Creative Commons Attribution License (CC BY). The use, distribution or reproduction in other forums is permitted, provided the original author(s) and the copyright owner(s) are credited and that the original publication in this journal is cited, in accordance with accepted academic practice. No use, distribution or reproduction is permitted which does not comply with these terms. 